\title{
A Experiência do ensino de filosofia feminista com uma perspectiva decolonial na educação popular em Florianópolis (SC)
}

Jeane Adre Rinque

\section{Resumo}

O objetivo da presente proposta é apresentar a experiência de educação popular no âmbito do Projeto Educação Comunitário INTEGRAR, fundado em 2011 em Florianópolis, uma iniciativa de professoras(os) voluntários reunidos com o propósito de uma educação consciente, crítica e cidadã junto a populações de periferia. O objetivo é uma prática de ensino de filosofia que introduz conceitos filosóficos também abordados por filósofas, dentro do programa das aulas na grade geral de ensino do projeto. A finalidade é dar visibilidade a filósofas e suas teorias, bem como analisar e recontar através de uma gramática filosófica (IRIGARAY, 2017;2018). Dentro de uma perspectiva decolonial (SPIVAK, 2010) que existe a possibilidade de discutir nossa colonialidade a partir de uma epistemologia feminista que está sempre em construção. Nesse caminho, o objetivo das aulas tem sido dialogar e refletir a partir de um pensamento com perspectiva de gênero construído a partir da leitura crítica de autores e temas considerados clássicos, apresentando autoras que igualmente abordam as diferentes temáticas, o que traz à sala de aula diferentes compreensões de mundo, uma vez que as contribuições das mulheres sempre estiveram presentes na história da humanidade, mas essa história sempre foi contada e escrita com uma visão da história hegemônica. Com isso a mulher e sua imagem foi castrada no período histórico, sem ter a chance de mostrar suas habilidades. Na perspectiva Freiriana (Freire,1987), a experiência aponta rumos a partir da metodologia de trocas de saberes com o(a)s estudantes. Com isso podemos contribuir para a construção de um 
pensamento e uma epistemologia rumo a autonomia e emancipação das mulheres.

Palavras chaves: educação popular; filosofia feminista; decolonial.

\title{
The experience of teaching feminist philosophy from a decolonial perspective in popular education of Florianópolis (SC)
}

\begin{abstract}
The purpose of this proposal is to present the experience of popular education within the scope of the INTEGRAR Community Education Project, founded in 2011 in Florianópolis - Brazil, an initiative of volunteer teachers gathered with the purpose of a conscious, critical and citizen education with populations from the periphery. The objective is a philosophy teaching practice that introduces philosophical concepts also addressed by philosophers, within the program of classes in the general teaching grid of the project. The purpose is to give visibility to philosophers and their theories, as well as to analyze and retell through a philosophical grammar (IRIGARAY, 2017; 2018). Within a decolonial perspective (SPIVAK, 2010), there is the possibility of discussing our coloniality from a feminist epistemology that is always under construction. In this way, the objective of the classes has been to dialogue and reflect from a thought with a gender perspective built from the critical reading of authors and themes considered classic, presenting authors who also address the different themes, which brings to the classroom different understandings of the world, since women's contributions have always been present in the history of mankind, but this history has always been told and written with a view of hegemonic history. With that, the woman and her image were castrated in the historical period, without having the chance to show her skills. In the Freirian perspective (Freire, 1987), the experience points out directions based on the methodology of exchanging knowledge with students. With this we can contribute to the construction of a thought and an epistemology towards the autonomy and emancipation of women.
\end{abstract}

Keywords: popular education; feminist philosophy; decolonial. 


\section{Introdução}

Desde 2018 sou professora voluntária de filosofia no Projeto de educação comunitária - INTEGRAR. Embora o projeto se constitua como um "cursinho pré-vestibular", cujos conteúdos seguem, de alguma forma, os programas/conteúdos dos processos seletivos, especialmente da Universidade Federal de Santa Catarina (UFSC) e da Universidade Estadual de Santa Catarina (UDESC), sua perspectiva de educação popular da pedagogia Freiriana permite-nos também construir outras reflexões mais amplas para além dos cânones teóricos.

Neste sentido, um dos exercícios pedagógicos que busco realizar em conjunto com as(os) alunas(os) é apresentar, diante dos "grande temas e autores" da filosofia , apresentar epistemologias alternativas aos pilares do pensamento e conhecimento eurocentrados. Deste modo, uma das reflexões iniciais vai no caminho de apresentar reflexões "de mulheres", feitas acerca dos mesmos temas abordados pelos "grandes clássicos", propondo assim apresentar no exercício do ensino de filosofia o que chamo aqui de epistemologia feministas; e num segundo momento busca é por introduzir também autoras (es) do sul global a partir de uma perspectiva decolonial do pensar.

O objetivo principal deste exercício pedagógico é, sem negar a vanguarda do pensamento filosófico, refletir sobre como os processos históricos euro-colonizadores - ao construir um sujeito universal do pensamento, do conhecimento e da reflexão - anula outras experiências, pensares e reflexões sobre o próprio mundo.

Sendo assim, apresento a seguir o relato da minha experiência como educadora popular. O texto foi composto por uma breve exposição sobre o projeto, sua história, como ele é estruturado, perfil dos alunos, objetivos do projeto; na sequência é apresentada minha relação de educadora com os educandos; após é discorrido qual a importância da disciplina de filosofia, bem como a importância da própria filosofia em nossas vidas e a valor de termos uma filosofia 
descolonizada; após comento como as aulas de filosofia são estruturadas, sendo em dois formatos, um que segue o programa dos vestibulares e o outro, por temas, que são abordados pelos próprios alunos, encerro com a conclusão da importância de termos uma filosofia descolonizada e na busca por termos uma filosofia feminista com uma perspectiva decolonial.

\section{Projeto de educação comunitária - INTEGRAR}

O projeto de educação comunitária integrar foi criado em agosto de 2011 por professores que queriam um curso pré-vestibular baseado nos princípios da educação popular. A finalidade era a inserção de trabalhadores, estudantes, negros, indígenas, LGBTQI+ e imigrantes, nas universidades públicas catarinenses através das políticas de cotas, uma vez que pessoas que estão em situação de vulnerabilidade social têm pouco acesso ao ensino. Desde sua criação o Integrar aprovou muitos alunos, em oito edições de vestibulares diferentes das universidades como UFSC / UDESC / IFSC / USJ em Santa Catarina e URGS no Rio Grande do Sul, de acordo com o número de alunos que já passaram pelo projeto, foram aprovados $42 \%$ deles, e isso para nós é muito significativo. Tendo em vista esse índice, fica evidente que a proposta de uma educação comunitária e popular voltada para as pessoas de baixa renda tem o potencial de inserir sujeitos em vários cursos de formação superior.

Atualmente as aulas do projeto acontecem de segundas a quintas-feiras, sendo que nas sextas-feiras é o dia escolhido para atividades extras, como cines debates, palestras, saída de campo, grupo de estudos, entre outros. As aulas do projeto ocorrem em três (3) salas cedidas pelo Instituto Estadual de Educação (IEE) e duas (2) salas cedidas pela Escola de Ensino Básico Jurema Cavalazzi, ambas em Florianópolis/SC. O corpo docente é formado por professores pósgraduados, graduados e professores em processo de formação. No decorrer desse período de existência do projeto nós professores 
percebemos as dificuldades de permanência no percurso formativo dos alunos, tanto no projeto, como a permanência na universidade, então na busca por uma solução, sensibilizamos na criação da GESTUS - Gestão Permanência Estudantil com o objetivo de garantir a permanência dos estudantes ajudando a superarem várias dificuldades encontradas no decorrer do curso como no auxílio a solicitação ao acesso à moradia, alimentação, materiais escolares, livros, informações acadêmicas, ajuda psicológica, etc.

O Integrar não possui o ingresso na universidade como seu único e principal objetivo, muito mais do que ingressar e acompanhar na universidade, o projeto busca formar os estudantes para que tenham uma visão crítica perante sociedade, buscando despertar o exercício da cidadania, intervenção social e atuação nos seus territórios. Considerando que, infelizmente, não é possível atender todos os estudantes que procuram vaga no Integrar, são realizadas seletivas para o ingresso dos estudantes, tanto na modalidade de extensivo e semiextensivo. Primeiro é necessário à inscrição no período determinado para tal, depois é realizada uma seleção para identificar os sujeitos que se encaixam no perfil do Integrar (trabalhadores, estudantes em situação de vulnerabilidade social, negros, indígenas, LGBTQI+ e imigrantes e pessoas acima da faixa etária do ensino regular, desempregados e outros). Após essa pré-seleção são realizadas entrevistas com os candidatos e por último é divulgada a lista dos selecionados. Por mais que o projeto não consiga abarcar toda a demanda necessária a existência de um espaço como esse se tornou um espaço de resistência e luta na cidade de Florianópolis.

Minha relação com o Projeto Integrar

Procurei o projeto Integrar pela proposta política pedagógicas, ambiente de trocas, autonomia para criar o plano de ensino que contemple tanto as demandas do vestibular como outros saberes. Percebo que os alunos não nos veem como meros professores, 
educadores populares, mas sim uma pessoa que está ali para defender uma causa social como forma de doação e sensível a sua condição. E neste momento parece nascer um grande sentimento de gratidão e empatia, criando uma relação de amizade e respeito. Os alunos não fazem conversas paralelas, são dedicados, levam em conta todo o contexto que estão inseridos e se esforçam para conseguir algo melhor através do aprendizado. As aulas de filosofia são ministradas em conjunto com a história, sociologia e geografia nas quartas feiras, sendo esta a noite das ciências humanas. O termo ciências humanas é utilizado, pois as essas disciplinas atuam conjuntamente nas aulas, com objetivo de trabalhar de forma interdisciplinar, fazendo com que os conteúdos ganhem mais sentido, uma vez que o aluno percebe o quanto os aprendizados podem fazer parte da própria existência.

\section{O Ensino de Filosofia}

A disciplina de filosofia é fundamental e indispensável para nosso processo de formação enquanto sujeito, pois através dela podemos ter uma visão mais global das coisas que permeiam o mundo. Ela também possibilita dialogarmos sobre nossa existência, razão e tudo que estaria no nosso campo de desejo, ela nos faz questionar conceitos, fatos, ideias, situações e valores que estão aí postos que também deverão ser questionados, é a forma de sair do senso comum e abrir para novos horizontes.

A filosofia força nossa lógica interna a sairmos das nossas posições pessoais, faz com que desvencilhamos dos preconceitos, da superficialidade; entretanto, o movimento filosófico praticado hoje, o nosso "jeito de filosofar" está atrelado ao processo colonizador europeu de ser, saber e fazer. Pensamos do ponto de vista grego de filosofar, como Platão, Aristóteles, céticos, medievos, empiristas e não percebemos que essa filosofia é uma filosofia hegemônica (CHAUI, 2014); e essa filosofia não deve ser a única forma de filosofar e reproduzir o conhecimento. 
Nosso modo de fazer filosofia também pode e deve ser feito de uma forma descolonizada, temos que alcançar outras formas de fazer filosofia, entender que a filosofia é flexível, abrir espaço para outros tipos de pensamento. O processo de colonização, fez com que tenhamos um problema sério de identidade (uma autoimagem negativa) de inferioridade. Penso que a construção da modernidade teve como primeiro momento histórico o surgimento do homem cartesiano de Descartes (penso logo existo - discurso do método - homem cartesiano/mente corpo) de modo a se abrir para a colonização do nosso pensamento. Quando a Europa se constitui o "centro" do saber, com essa nova história mundial, se inaugurou e consolidou para nós aqui nas américas esse modo de pensamento, onde constituiu um espaço não só de exploração de um povo escravizado, de dominação do território, controle das estruturas sociais, mas também como intervenção sobre como o povo produzia o conhecimento e consequentemente interferiu nossa forma de pensar filosoficamente. Acredito que a partir do surgimento da modernidade todo um processo constituído no processo de colonização se abre para um novo modo de fazer filosofia Mito da modernidade (DUSSEL, 1993).

A invasão das américas se constituiu em dominar o conhecimento os saberes do nosso território, também fez distinção de gênero, levando as relações humanas a ser reconhecidas em termos biológicos. Para as mulheres, a colonização foi um processo duplo de interiorização e subordinação de gênero uma vez que além de sofrer opressão por parte do colonizador também sofre por parte do colonizado.

Por isso, o pensar uma filosofia feminista a partir de uma perspectiva decolonial é pensar na sujeita do discurso e da enunciação. Mesmo que continuamente colocadas de uma forma inferiorizada à margem na história, as mulheres sempre estiveram presentes na história da humanidade, e escrever uma nova epistemologia é contar, reparar a nossa verdadeira história: de nós mulheres e da humanidade como um todo. Romper o silêncio é questionar a cultura falocêntrica imposta, é 
resgatar o que nos foi negado nesse longo período histórico. (IRIGARAY, 2002)

Experiência de uma filosofia feminista

Diante do exposto, penso que é importante dizer que - não só no interior do Projeto Integrar, mas - especialmente enquanto mulherfeminista-lésbica meu saber situado exige que experiência enquanto educadora popular proporcione a organização de um plano de ensino anual de uma forma mais didática e emancipatória.

Sendo assim, criei dois formatos de aula.

O primeiro de acordo com o que está programado no edital da disciplina de filosofia de vestibulares, como UFSC / UDESC, onde o programa é pautado por uma filosofia clássica e tradicional, com temas dos cânones da filosofia - A República de Platão, os contratualistas Thomas Hobbes, John Locke, Jean-Jacques Rousseau que abordam temas sobre a natureza humana e contrato social, trazem também como temas sobre a ética com Immanuel Kant (imperativo categórico), bem como Aristóteles e o conceito do que é "filosofia". Essas aulas são preparadas com o intuito de, além de trazer os filósofos apresentados que subsidiará os alunos a responderem as questões do vestibular, fazer um contraponto com esses filósofos, para que os alunos saibam que além dos cânones existem outras contribuições para os temas e essas contribuições são feitas por filosofas (mulheres). Com isso, podemos tratar a filosofia clássica, não só como centro do conhecimento, mas como ponto de partida para introduzir discussões acerca das produções realizadas por filosofas mulheres.

O segundo formato de aula, se dá fora do programa de vestibular. Procuro abordar temas que fazem parte do cotidiano dos alunos, temas que são escolhidos por eles mesmos no primeiro dia de aula da disciplina de filosofia, esses temas vêm decorrente a uma roda 
de conversa "do que é filosofia" geralmente os temas variam de acordo com o ano letivo.

Abaixo exploro mais detalhadamente como organizo, na prática os programas de aula.

Formato 1 - Conforme explanei acima, esse primeiro formato de aula parte dos temas que estão inseridos no programa da disciplina de filosofia de vestibulares das universidades UFSC/UDESC, geralmente pautado por uma filosofia clássica e tradicional trazendo temas dos cânones da filosofia.

Aula 1 e 2 - Conceito sobre "o que é filosofia", é apresentado o conceito grego de filosofia como "ciência primeira" do livro gama de Aristóteles, filosofo grego; na sequência é abordado o conceito da filosofia da América latina de Enrique Dussel filosofo latino-americano; e, por fim, o conceito "Pode o subalterno falar" de Gayatri Spivak filosofa Indiana. Conclui-se a aula com uma atividade filosófica de pensar o cotidiano dos alunos trazendo temas que fazem parte do dia-a-dia que poderia ser incluído no programa de aulas que não estão inseridas no programada dos vestibulares.

Aula 3 - sobre "A República de Platão" é abordado o tema da democracia ateniense: o que é uma cidade justa, ética platônica, etc.; e na sequência é apresentada a contribuição da pensadora Suzan Okin filosofa neozelandesa, que dialoga contemporaneamente com Platão sobre o livro $\mathrm{V}$ da Republica. Ela irá refletir diretamente na vida das mulheres, dentro dessa democracia ateniense.

Aula 4 - 5 e 6 - nas aulas sobre Os Contratualistas - Thomas Hobbes, John Locke, ambos filósofos ingleses, Jean-Jacques Rousseau filósofo 
Suíço, é feito, num primeiro momento, uma breve contextualização histórica sobre revolução francesa e iluminismo. Considerando que são aulas interdisciplinares e tais temas já devem ter sido tratados pela equipe de história Os temas filosóficos abordados são sobre a natureza humana, leviatã (Estado), a importância da obra "ensaio acerca do entendimento humano" e o contrato social. Para concluir a aula, é apresentada a teoria "contrato sexual" de Carole Pateman filósofa britânica, uma vez que ela faz críticas ao liberalismo e tem perspectivas feministas a respeito da dominação e do contrato social entre gêneros.

Aula 7 - O debate acerca da "Ética" a partir das discussões de Immanuel Kant, filosofo Prussiano, gira em torno da abordagem sobre os tipos de ética (normativa e deontológica), além disso é contextualizada a ética kantiana partindo do imperativo categórico. Num segundo momento, são expostas as contribuições para a ética Kantiana das autoras Barbara Herman e Christine Korsgaard, ambas filosofas estadunidenses que trazem contribuições acerca da filosofia moral e da ética Kantiana.

Aula 8 - A aula sobre Karl Marx é interdisciplinar e em conjunto com a equipe de sociologia. Neste tópico eles abordam os conceitos de "propriedade privada dos meios de produção", "acumulação ilimitada de capital", de modo que na aula de filosofia é feito um breve histórico sobre o tema. Neste momento é pontuado as contribuições de Nancy Fraser, filosofa estadunidense, no que tange a "Justiça de gênero" em que a pensadora feminista, argumenta que a justiça é um conceito complexo que deve ser entendido sob três dimensões separadas, embora inter-relacionadas: distribuição (de recursos produtivos e de renda), reconhecimento (das contribuições variadas dos diferentes grupos sociais) e representação (na linguagem e em todo o domínio do simbólico). 
Formato 2 - Esse segundo formato de aula, está fora do programa das disciplinas do vestibular e é escolhido a partir de assuntos do cotidiano dos alunos, temas que - conforme discorri acima - são escolhidos por eles nas aulas 1 e 2 sobre o conceito "O que é filosofia". Os temas podem ser variados de acordo com o ano letivo. No ano de 2019 foram abordados os seguintes temas.

1) - violência do estado; 2) - direito das mulheres; 3) -sexualização das mulheres no funk e 4) - feminismo. Pensou-se em um programa de aula conforme a ordem dos temas, conforme segue:

Aula 8 - (tema 1: Banalidade do Mal) -abordamos as discussões de Hannah Arendt, filosofa judia/Alemã, que trata assunto da condição humana e sobre o conceito da banalidade do mal. O tema permite ainda discutir sobre a violência do estado frente as populações periféricas, bem como a realidade dos jovens negros.

Aula 9 - (tema 2: "A Reivindicação dos Direitos das Mulheres") - O texto de Mary Wollstonecraft, filosofa inglesa, que nos permite fazer reflexões sobre o direito das mulheres, antes de apresentar a obra é feita uma breve contextualização sobre a declaração Universal dos Direitos Humanos, que delineia os direitos humanos básicos, além disso é contextualizado sobre a Lei Maria da Penha 11340/06.

Aula 10 - (tema 03: Estética) nessa aula é abordada o conceito de arte, períodos filosóficos da arte, bem como o conceito de estética quanto percepção sensível; sobre o "belo e o feio" - questão de gosto -, apreensão estética, atitude estética, e como aprendizado experiencial dentro da perspectiva apresentada é debatido sobre o "FUNK": se é arte ou não e qual a influência desse estilo na realidade, vivencias dos alunos, e como é visto a subjugação da imagem da mulher nas letras de algumas vertentes do funk. 
Aula 11 - (tema 4: Feminismo) - trata-se de uma discussão acerca história dos feminismos, sobre as ondas e vertentes, incluindo, especialmente, as discussões sobre feminismo decolonial e subalterno.

\section{Conclusão}

É evidente que estes dois anos de experiência como professora de filosofia junto ao Projeto INTEGRAR me oportunizaram, muito mais que ensinar, traz um aprendizado diário. A troca entre as (os) professoras (es) / professoras (es) e alunas (os) é um reconhecer-se no mundo constantemente. E, este exercício de reflexões e questionamento dos cânones/temas clássicos faz parte deste processo.

Penso que a maior contribuição vindoura desta busca por uma alternativa pedagógica à epistemologia filosófica estabelecida é despertar entre as (os) alunas (os) a compreensão de que elas (es) são parte destas reflexões. Elas (es) podem ser (e são) ao mesmo tempo sujeitos e agentes destas teorias. E que elas próprias podem (e devem) ser orgânicas e vivas. Pois os "grandes temas clássicos" dizem sobre o realizar-se no mundo, em constância.

Além disso, a busca por romper com a lógica do pensamento/sujeito universal do pensar filosófico - embora não inédito - parece ainda mais pertinente quando busca aproximar " $\mathrm{A}$ " filosofia de realidades tangíveis. Sendo assim, esta primeira ruptura se estabelece ao questionarmos o agente euro-masculino do saber, e apresentar autoras, mulheres, que refletem sobre os mesmos temas. E uma segunda, ainda em exercício e necessário maiores práticas pedagógicas, busca propor reflexões que também rompam com a lógica colonial e colonizada do pensamento. Deste modo, estas (es) sujeitas (os) - eu, demais 
professoras (es), e alunas (os) - somos parte destes seres "subalternos" invisibilizadas(os), somos agentes reflexivos, e como nós várias(os) outras(os) autoras(es) do sul global devem ser incorporadas(os) em novas aulas.

\section{Referencias}

ARANHA, Maria Lúcia de Arruda, Filosofando: Introdução à Filosofia/ Maria Lúcia de Arruda Aranha, Maria Helena Pires Martins. 4.ed. São Paulo: Moderna 2009

CHAUÍ, Marilena. Conceito de Hegemonia em Gramsci por Marilena Chauí - Publicado por CPINFO, 13 fev. 2014. Disponível em: https://www.ufmg.br/proex/cpinfo/cidadania/?p=152. Acesso em: 20 ago. 2020.

CORTÉS, Olga Nancy Pena. A filosofia feminista de Luce Irigaray Kalagatos revista de filosofia - UECE Fortaleza -CE - 2018

DUSSEL, Enrique. 1942 O Encobrimento do Outro - Mito da Modernidade. In: Conferências de Frankfurt. Tradução Jaime A. Clasen. Petrópolis RJ: Vozes, 1993.

DUSSEL, Enrique. Filosofia da Libertação - Filosofia na América Latina. Tradução Luiz João Gaio. São Paulo SP: co-edição Loyola - Unimep 1977.

LUCAS, Angioni. ARISTÓTELES, Metafísica Livro IV Gama, Livro VI Epsilon - Departamento de Filosofia - Instituto de Filosofia e Ciências Humanas - IFCH - UNICAMP, set. 2007.

PATEMAN, Carole. O contrato Sexual. Tradução de Marta Avancini. Rio de Janeiro: Paz e Terra, 1993.

SPIVAK, Gayatri Charkravorty. Pode o subalterno falar? Tradução de Sandra Regina Duarte, Marcos Pereira, André Pereira Feitosa. Belo Horizonte: Editora UFMG, 2010. 